\title{
Workshop report from the National Institutes of Health Taskforce on the Research Needs of Eosinophil-Associated Diseases (TREAD)
}

\section{Citation}

Bochner, Bruce S., Wendy Book, William W. Busse, Joseph Butterfield, Glenn T. Furuta, Gerald J. Gleich, Amy D. Klion, et al. 2012. Workshop Report from the National Institutes of Health Taskforce on the Research Needs of Eosinophil-Associated Diseases (TREAD). Journal of Allergy and Clinical Immunology 130, no. 3: 587-596. doi:10.1016/j.jaci.2012.07.024.

\section{Published Version}

doi:10.1016/j.jaci.2012.07.024

\section{Permanent link}

http://nrs.harvard.edu/urn-3:HUL.InstRepos:32306652

\section{Terms of Use}

This article was downloaded from Harvard University's DASH repository, and is made available under the terms and conditions applicable to Other Posted Material, as set forth at http:// nrs.harvard.edu/urn-3:HUL.InstRepos:dash.current.terms-of-use\#LAA

\section{Share Your Story}

The Harvard community has made this article openly available.

Please share how this access benefits you. Submit a story.

Accessibility 


\title{
Workshop Report from the NIH Taskforce on the Research Needs of Eosinophil-Associated Diseases (TREAD)
}

\author{
Bruce S. Bochner, MD ${ }^{a}$, Wendy Book, MD ${ }^{b}$, William W. Busse, MD $^{c}$, Joseph Butterfield, \\ MD $^{d}$, Glenn T. Furuta, MD ${ }^{e}$, Gerald J. Gleich, MD ${ }^{\dagger}$, Amy D. Klion, MD ${ }^{g}$, James J. Lee, PhD ${ }^{h}$, \\ Kristin M. Leiferman, MD $^{f}$, Michael Minnicozzi, PhDi, Redwan Moqbel, PhD, FRCPath ${ }^{j}$, Marc \\ E. Rothenberg, MD, PhD ${ }^{k}$, Lawrence B. Schwartz, MD, PhD $^{\prime}$, Hans-Uwe Simon, MD, PhD $^{m}$, \\ Michael E. Wechsler, MD $^{n}$, and Peter F. Weller, MD ${ }^{\circ}$ \\ ${ }^{a}$ Department of Medicine, Division of Allergy and Clinical Immunology, Johns Hopkins University \\ School of Medicine, Baltimore
}

${ }^{\mathrm{b}}$ American Partnership For Eosinophilic Disorders, Atlanta

'Department of Medicine, Division of Allergy and Clinical Immunology, University ofWisconsin School of Medicine and Public Health, Madison

dDepartment of Medicine, Division of Allergic Diseases, Mayo Clinic, Rochester

eDigestive Health Institute, Section of Pediatric Gastroenterology, Hepatology and Nutrition, Gastrointestinal Eosinophilic Diseases Program, The Children's Hospital, National Jewish Health, Mucosal Inflammation Program, Department of Pediatrics, University of Colorado School of Medicine, Aurora

fDepartment of Dermatology, University of Utah, Health Sciences Center, Salt Lake City

gLaboratory of Parasitic Diseases, National Institute of Allergy and Infectious Diseases, National Institutes of Health, Bethesda

hDepartment of Biochemistry and Molecular Biology, Division of Pulmonary Medicine,Mayo Clinic Arizona, Scottsdale

iNational Institute of Allergy and Infectious Diseases, National Institutes of Health, Bethesda

(C) 2012 American Academy of Allergy, Asthma and Immunology. Published by Mosby, Inc. All rights reserved.

Correspondence to: Bruce S. Bochner, MD, Cosner Scholar in Translational Research, Professor of Medicine and Director, Division of Allergy and Clinical Immunology, Johns Hopkins Asthma and Allergy Center, 5501 Hopkins Bayview Circle, Baltimore, Maryland 21224-6821, Phone 410-550-2101, FAX 410-550-1733, bbochner@jhmi.edu.

Publisher's Disclaimer: This is a PDF file of an unedited manuscript that has been accepted for publication. As a service to our customers we are providing this early version of the manuscript. The manuscript will undergo copyediting, typesetting, and review of the resulting proof before it is published in its final citable form. Please note that during the production process errors may be discovered which could affect the content, and all legal disclaimers that apply to the journal pertain.

Conflict of Interest statements: Dr. Bochner has served, or currently serves as a consultant for Sanofi-Aventis, Genentech, Merck, Roche and GlaxoSmithKline, and is a co-inventor on existing and pending Siglec-8-related patents. Dr. Bochner may be entitled to a share of royalties received by the University on the potential sales of such products. Dr. Bochner is also a co-founder of, and owns stock in, Allakos, Inc., which makes him subject to certain restrictions under University policy. The terms of this arrangement are being managed by the Johns Hopkins University in accordance with its conflict of interest policies.

Dr. Weller has served as a consultant for GlaxoSmithKline.

Dr. Simons has ongoing consulting arrangements with Pfizer.

Dr. Rothenberg has an equity interest in reslizumab (Teva Pharm), and is a consultant and Chief Scientific Officer for Immune Pharmaceuticals, and is the inventor on numerous eosinophil associated patents owned by Cincinnati Children's Hospital. Dr. Schwartz serves as a consultant for Sanofi-Aventis, Marshall Edwards and Genentech; performs clinical trials for Novartis, GlaxoSmithKline, Green Cross and Genentech; investigator-initiated research funded by Carolus and NeilMed; and is an inventor of tryptase assays and monoclonal antibodies against tryptase, chymase and the intermediate form of major basic protein for which Virginia Commonwealth University receives royalties from ThermoFisher, Millipore, Santa Cruz, Hycult and BioLegend that are shared with Dr. Schwartz. 


\author{
jDepartment of Immunology, University of Manitoba, Faculty of Medicine,Winnipeg \\ kthe Division of Allergy and Immunology, Department of Pediatrics, Cincinnati Children's Hospital \\ Medical Center, University of Cincinnati College of Medicine, Cincinnati \\ 'Department of Internal Medicine, Division of Rheumatology, Allergy \& Immunology, Virginia \\ Commonwealth University, Richmond \\ mInstitute of Pharmacology, University of Bern, Bern \\ nDepartment of Medicine, Division of Pulmonary and Critical Care, Brigham and Women's \\ Hospital, and Harvard Medical School, Boston \\ 'Department of Medicine, Division of Allergy and Inflammation, Division of Infectious Diseases, \\ Beth Israel Deaconess Medical Center, Harvard Medical School, Boston
}

\title{
Abstract
}

Background-Eosinophils are blood cells that are often found in high numbers in the tissues of allergic conditions and helminthic parasite infections. The pathophysiological roles that eosinophils may serve in other human 'eosinophil-associated' diseases remain obscure.

Objective-NIH Institutes and the Office of Disease Prevention assembled an international taskforce of clinical and basic scientists with the charge to propose and prioritize unmet research needs in eosinophil-associated diseases.

Methods-The taskforce used an organ system approach to dissect out the different and common themes of eosinophil cell involvement in these diseases. In early 2012, a draft document was circulated for review. The document was amended and the prioritizations were set at a NIHorganized workshop in June 2012.

Results-The taskforce identified significant research needs. These needs cross disease entities but some are disease-specific. There are substantial shortcomings to the various preclinical animal models, as well as significant gaps in our epidemiologic, pathophysiologic, diagnostic, prognostic and therapeutic knowledge. The taskforce recognized that recent efforts by patient advocacy groups have played instrumental roles in improving the identification and characterization of these disorders. However, communication amongst the eosinophil interested communities, e.g., governmental funding and regulatory agencies, and industry and clinician scientists need to be more comprehensive.

Conclusions-Significant efforts are required to address our knowledge gaps in order to improve the outcomes of eosinophil-associated diseases. NIH Institutes, other federal agencies, lay organizations and the pharmaceutical industry should consider the taskforce's recommendations in their future research activities.

\section{Keywords}

eosinophil; apoptosis; therapeutics; research; discovery; fusion oncoproteins; hypereosinophilic syndromes; Churg-Strauss syndrome; coagulopathy

\section{Introduction}

"Eosinophil-associated diseases" is a term that is used to describe a group of uncommon medical conditions in which the eosinophil, one of the less prevalent blood leukocytes, is considered to have a primary or an important pathophysiologic role (Table 1). ${ }^{1}$ Such disorders can impact the skin, upper and lower airways, cardiovascular system, connective tissues, gastrointestinal tract, the hematopoietic and immune systems and other organs 
(Figure 1). ${ }^{2}$ However, despite the abundance of eosinophils, the pathophysiological roles that these cells play in these diseases are not well understood. Moreover, treatment options are relatively limited. On-going clinical research, including clinical trials, supported by governmental and non-governmental organizations and by the pharmaceutical industry, is inadequate. From a patient's perspective, not only the limited treatment options, but also physicians' limited knowledge of eosinophil-associated diseases can be detrimental to physical and psychological health and can result in substantial quality of life restrictions. This can also impact the emotional and social lives of the patients' families.

\section{Objectives}

On June 4, 2012 a workshop was convened in Bethesda, MD by a consortium of several National Institutes of Health (NIH) Institutes and the Office for the Prevention of Diseases for the purpose of defining, clarifying and prioritizing the unmet research and supportive needs of eosinophil-associated diseases. This report should help promote the translation of research into clinical practice and health policy. The responsibility for this workshop report and recommendations is solely that of the taskforce convened. The workshop report is not an official document of any government agency.

\section{Background and Approach}

Eosinophils are bone marrow-derived blood cells that migrate to specific tissues of normal, healthy individuals, namely the gut, mammary glands, uterus and thymus. This localization is most likely under the control of the chemokine, eotaxin- $1 .{ }^{3}$ It is unlikely that eosinophil presence in the thymus, an immunologically critical organ, is a result of an inflammatory response as recent studies have confirmed abundance of these cells post-natally and over the first decade of life. ${ }^{4}$ Thymic eosinophils constitutively express indolamine 2,3 dioxygenase (IDO), which suggests they may serve an immune regulatory/modulatory role. ${ }^{5}$ Eosinophils are also often increased in other tissues (e.g., airways or skin), when associated with allergic conditions such as asthma or parasitic infections. ${ }^{6,7}$

Substantial information has been gained from preclinical modeling about the potential roles of eosinophils as immune cells. Specifically, mouse models have been particularly valuable as both the starting point and as a confirmation of insights derived from studies of human tissues/cells. The availability of mice that congenitally lack eosinophils has helped in the definition of the immunoregulatory capacities of these cells and their roles in Th2-driven allergic inflammation. ${ }^{8,9}$ Building on these preclinical observations, Lee et al have proposed a provocative hypothesis that eosinophils may serve complex roles in human health and disease. In their LIAR (local immune and remodeling) hypothesis, eosinophils are proposed to have evolved as local regulators of some aspects of immune function and tissue remodeling and their functions are likely to have multiple effects on and to be influenced by their tissue microenvironment. ${ }^{10}$ The effects of eosinophils may go well beyond the regulation of traditional events that are thought of as immune responses. Other investigators have now suggested that eosinophils may regulate glucose metabolism in adipose tissue, induce plasma cell maintenance in the bone marrow, induce apoptosis of human Th1 cells, play a role in transplant rejection, affect the neuropathology of multiple sclerosis, provide cancer surveillance and suppress helminthic parasites. ${ }^{11-16}$

With this information in hand, the taskforce examined eosinophil involvement in a variety of processes, through an organ-system based approach, detailing some of the current state of medical and research knowledge but mostly focusing on unmet needs. Specifically, this report addresses human eosinophil-associated diseases in the gastrointestinal system, skin, respiratory, cardiovascular system and the blood. However, the taskforce acknowledges that, in many of these conditions, organ systems are not affected in an exclusive manner, but that 
multi-system involvement is often encountered. The participating federal agencies and other medical research organizations should consider this report as a selective set of recommendations for priorities that will generate answers to the unmet needs of eosinophilassociated diseases.

\section{Review and Results}

\section{Diagnostic Codes for Eosinophil-Associated Diseases}

Even with documentation of significant elevation in the number of circulating eosinophils, clinicians often fail to take this information into account in their diagnostic process. This reflects inadequate medical education on eosinophil-associated diseases, but also inadequate diagnostic coding. Currently, the International Classification of Diseases, Clinical Modification, based on the World Health Organization's Ninth Revision, includes diagnostic codes that are used for various eosinophil-associated disorders (ICD-9 CM; Table 1).

However, in examining the current code list, the taskforce noted that many eosinophilic disorders, including Churg-Strauss Syndrome (CSS), hypereosinophilic syndromes, eosinophilic fasciitis, and eosinophilic pneumonia do not have their own ICD-9 CM codes, but are lumped together with other disorders. ICD-9 CM codes are critical for the purpose of reporting and tracking information such as the incidence and prevalence of specific disorders. Furthermore, the availability of such codes makes it easier for medical professionals and researchers to accurately document individuals with these conditions. The taskforce points out that the lack of eosinophil-associated disease-specific ICD-9 CM codes precludes determination of the true prevalence of specific eosinophil-associated diseases. Lack of such epidemiologic information may have a negative impact on the development and approval of novel eosinophil-targeted therapeutics. Another negative impact of the lack of specific ICD-9 CM codes is that it hinders medical insurance reimbursements leading to problems with patient care. It is also worth mentioning several other eosinophil-associated disorders including eosinophilic esophagitis and related eosinophilic gastrointestinal disorders (EGIDs) were not assigned unique ICD-9 CM codes until 2008. This seemingly simple advance was brought about in large part by efforts of the patient advocacy groupAmerican Partnership for Eosinophilic Disorders (see www.apfed.org).

\section{Eosinophil Gastrointestinal Disorders (EGIDs)}

EGIDs are a heterogeneous group of disorders characterized by a wide range of symptoms associated with a dense eosinophilic inflammation of the gastrointestinal tract. ${ }^{17}$ The location of the eosinophilic inflammation has been used to define the type of EGID.

Eosinophilic esophagitis (EoE) is characterized by symptoms of esophageal dysfunction. ${ }^{18,19}$ Prevalence has been estimated to range from as high as 1-4 in 1,000 to 1 in 70,000 children and adults. Symptoms are often attributed to gastroesophageal reflux disease (GERD), but they do not resolve with typical medical or surgical treatments used for GERD. Blood eosinophil levels may be increased but are not typically pronounced. Histological findings on endoscopic biopsies encompass a number of features that are indicative of inflammation with the presence of an increased number of eosinophils, eosinophilic microabscess formation and eosinophil degranulation. Other aspects of chronic inflammation, including tissue damage and remodeling, may be present. In addition to eosinophils, mast cells, epithelial cells, eotaxin-3 and interleukin (IL)-13 are among the cells and molecules that have been implicated in EoE disease pathogenesis. ${ }^{20,} 21$

The impact of the disease on growth and development in children is evident; foods appears to play a prominent causative role in pediatric and adult patients. ${ }^{22,23}$ While there are differences in symptomatology, it is unknown whether adult and pediatric onset EoE 
diseases are entirely different conditions or a spectrum of the same disease. Persistence of EoE from childhood into adulthood is common based on a retrospective 17-year longitudinal study of esophageal eosinophilia from childhood into adulthood. ${ }^{24}$

Eosinophilic gastritis, enteritis, and colitis are less common than EoE and are characterized by symptoms of diarrhea, abdominal pain, and malnutrition, and in some cases, bleeding. ${ }^{17}$ Laboratory blood analysis may show evidence of anemia, hypoalbuminemia, and substantial peripheral eosinophilia. Endoscopic findings include edema, polyp formation and ulceration with histological examination revealing dense eosinophilic inflammation of the mucosa and architectural changes in the gastrointestinal tract, including cryptitis.

The exact etiology of each form of EGID is not certain, but the prevalence, at least for EoE, has dramatically increased over the past few decades, due in large part to increased disease recognition. ${ }^{25}$ The potential for an allergic etiology is supported by the reversibility of the disease following dietary avoidance of specific foods, reoccurrence of the disease upon reintroduction of the removed foods, induction of the disease in mice by exposure to allergens, and genome-wide transcriptome analysis of esophageal tissue, implicating adaptive $\mathrm{T}$ helper cell type 2 (Th2) immunity. ${ }^{26,27}$ There is a strong genetic component to EoE, with a large sibling risk ratio and the presence of susceptibility loci in candidate genes expressed by esophageal epithelial cells such as genes and/or loci for thymic stromal lymphopoietin (TSLP), cytokine receptor-like molecule 2 (CRL2) (encoding for the TSLP receptor), CCL26, and filaggrin. ${ }^{17,}{ }^{28}$ Current therapy for EoE consists of food avoidance and/or the use of swallowed corticosteroids. ${ }^{29}$

The taskforce recommends that future efforts should aim at:

- developing the best method(s) for disease diagnosis that would include exclusion of esophageal acid/nonacid disease as the cause of EoE (e.g., proton-pump inhibitor (PPI) therapy and diagnostic testing)

- developing and validating criteria for the diagnosis of eosinophilic diseases outside of the esophagus

- examining the relationship of EGIDs to other inflammatory bowel diseases

- examining and validating testing methodologies for adults and children to be used in guiding dietary exclusion protocols

- determining the optimal frequency and validating the outcomes of endoscopic follow-up

- elucidating the mechanistisms leading to the breakdown in oral food tolerance

- improving our understanding of the mechanisms and preventing tissue remodeling, stricture formation and other complications

- developing better preclinical models of EGIDs

\section{Eosinophil-Associated Cutaneous and Fibrotic Diseases}

Wells syndrome, or eosinophilic cellulitis with flame figures in lesions, is primarily a disease of adults. Whether Wells syndrome is a specific entity that is triggered by factors including underlying disease, infection, and drugs, or whether it is merely a reaction pattern is difficult to discern from the reported cases and in practice. ${ }^{30}$ Association of eosinophilic cellulitis with a range of disorders suggests that it is a reactive or allergic hypersensitivity phenomenon. 
Angiolymphoid hyperplasia with eosinophilia occurs in both males and females and has no racial preference. While benign, it shows a predilection for the head and neck area, including the ears, and is characterized by solitary, few, or multiple, sometimes grouped, erythematous, violaceous or brown papules, plaques, or nodules of the dermis and/or subcutaneous tissues and is often disfiguring. ${ }^{31}$ The condition has been considered a vascular proliferation arising in response to, or in association with, underlying vascular malformation.

Kimura's disease occurs predominantly in young adult Asian males. It also has been reported in non-Asians and in children. Patients typically have one or a few asymptomatic, non-tender, slowly enlarging subcutaneous nodules. Lesions characteristically involve the head and neck region but may be localized to the extremities, axilla, groin, or trunk, and are associated with peripheral blood eosinophilia and elevated serum total IgE. Histologically, lesions are characterized by lymphoid aggregates, usually in the form of lymphoid follicles with germinal centers, numerous eosinophils, and fibrosis. ${ }^{32}$

Episodic angioedema associated with eosinophilia is characterized by recurrent angioedema (with up to 30 percent increase in body weight), urticaria, fever, increased serum IgM levels, and leukocytosis as high as 100,000 cells $/ \mathrm{mm}^{3}$ with up to 90 percent eosinophils; disease activity fluctuates with the peripheral eosinophil count. ${ }^{33}$ Tissue histological samples show few eosinophils, but immunofluorescence staining reveals extracellular deposition of eosinophil granule proteins around collagen bundles and blood vessels. ${ }^{34}$ The syndrome is associated with a number of immunologic abnormalities, including increased activated T cells and increased serum IL-5 levels. ${ }^{35}$

Numerous eosinophil associated fibrotic syndromes are recognized, including eosinophilic fasciitis, retroperitoneal fibrosis, mediastinal fibrosis, fibrosing thyroiditis and sclerosing cholangiitis. Patients presenting with Eosinophilic fasciitis (Shulman syndrome) have symmetrical thickness and hardening of the skin, especially of the forearms, with peripheral blood eosinophilia often reaching levels associated with the hypereosinophilic syndrome (greater than $1500 / \mu \mathrm{L}$ ). ${ }^{36,37}$ Eosinophilic fasciitis usually presents with pain, erythema, edema, and induration of the extremities, as well as peripheral blood eosinophilia and hypergammaglobulinemia. Contractures and rippling of the skin may develop. As the disease progresses, fibrous tissue deposition increases leading to restriction of joint motion, carpal tunnel syndrome and an inflammatory arthritis. ${ }^{34}$ When hypergammaglobulinemia is present, IgG and C3 depositions have been identified in the fascia of some patients. Treatment is usually glucocorticoid administration, and, in many cases, this is sufficient.

Blood and tissue eosinophilia have also been associated with retroperitoneal fibrosis, sclerosing cholangiitis, Riedel's thyroiditis, sclerosing mediastinitis, orbital pseudotumor and pulmonary fibrosis. ${ }^{38}$ Other eosinophil-associated fibrotic diseases include the Spanish toxic oil syndrome and the eosinophilia myalgia syndrome. While these syndromes occurred as epidemics and both ran their courses, they were associated with the occurrence of fibrosis especially eosinophilic fasciitis. The eosinophilia myalgia syndrome, which is historically related to ingestion of certain lots of L-tryptophan, is characterized by marked peripheral eosinophilia, disabling generalized myalgias, pneumonitis, myocarditis, neuropathy, encephalopathy, and fibrosis, a constellation of features that are similar to, but are distinguishable from eosinophilic fasciitis. ${ }^{39}$

In all of the skin and fibrotic conditions discussed, the precise pathogeneses are unknown and the absence, presence and number of eosinophils in skin biopsies are often of limited value. Yet, even when intact eosinophils are not observed in tissues, the deposition of their 
toxic granule proteins, revealed by immunofluorescence testing, supports the premise of their involvement. 40

The taskforce recommends that future efforts should aim at:

- $\quad$ improving the mechanistic understanding of the role of eosinophils in cutaneous disease

- $\quad$ determining if these diseases are skin-specific or manifestations of underlying systemic disorders

- developing, standardizing and validating methods for biopsies of skin and for detection of extracellular deposition of eosinophil granule proteins even in the absence of tissue eosinophilia.

The taskforce also recognizes that some of these diseases have appeared in the form of an epidemic and that future, similar epidemics could be encountered. In this respect, a recommendation of the taskforce is that, in the future, adequate responses to eosinophilassociated epidemic diseases with sufficient support for rapid investigations including epidemiology and pathophysiology of the outbreak needs to be mounted.

\section{Eosinophil-Associated Cardiovascular Disorders}

The heart is an organ that is subject to involvement and damage in the setting of diverse eosinophil-associated diseases, including CSS, in which eosinophilic infiltration of small blood vessels in the myocardium and pericardium and/or eosinophilic infiltration of the coronary arteries, can lead to potentially fatal outcomes. ${ }^{41}$ In fact, up to $50 \%$ of the patients who die from CSS have evidence of myocardial involvement and $15 \%$ have pericardial involvement. In other eosinophil-associated diseases, ranging from drug hypersensitivity reactions to varied hypereosinophilic syndromes, damage to the heart, varying from early necrosis to subsequent thrombosis and fibrosis, is often indistinguishable. Enigmatically, some patients with sustained eosinophilia never develop cardiac disease.

Eosinophil-mediated heart damage typically evolves through three stages: an acute necrotic stage, a thrombotic stage and finally, a fibrotic stage. In the acute stage, the duration of illness is short and is usually neither clinically recognized nor diagnosed as echocardiography and angiography detect no abnormalities. Troponin levels are often elevated, however, and damage to the endocardium is common with histopathologic evidence of myocardial necrosis with eosinophil infiltration and degranulation. Assays of serum troponins, which reflect early myocardial damage, provide a more sensitive detection method for early eosinophil-associated myocardial damage.

After months of eosinophilia, the second stage of heart disease involves the formation of thrombi along the damaged endocardium of the ventricles and occasionally the atria. In the third and final fibrotic stage, progressive scarring develops that may lead to entrapment of the chordae tendinae with the development of mitral and/or tricuspid valve regurgitation and to endomyocardial fibrosis producing a restrictive cardiomyopathy. Patients with late stage eosinophilic heart disease may require bioprosthetic valve replacement when hemodynamically necessary.

The risks of developing cardiac disease are not simply related to the extent or duration of eosinophilia. For example, in contrast to patients with CSS, patients with eosinophilic pneumonia and EGIDs, rarely, if ever, develop cardiac involvement. Early diagnosis and management of eosinophil-mediated cardiac damage could diminish the morbidity, potential mortality and the expenses associated with late stage cardiac surgery. 
The taskforce recommends that future efforts should aim at:

- improving and validating non-invasive diagnostic testing for eosinophil-induced cardiac damage

- improving therapies that prevent or block the progression of eosinophil-mediated cardiac damage

- understanding the mechanisms of eosinophil-mediated cardiac damage

- developing the best preventive and acute treatment approaches for patient care

- generating preclinical models that exhibit eosinophil-mediated cardiac damage

\section{Eosinophil-Associated Disorders of the Hematopoietic System}

Eosinophilic disorders of the hematopoietic system can be now separated into intrinsic and extrinsic. Chromosomal abnormalities have been reported in patients with intrinsic hypereosinophilic syndromes (HES). ${ }^{42}$ An example of an extrinsic disorder is "lymphocytic variant" HES that is due to polyclonal expansion of eosinophils due to the overproduction of IL- 5 by T cells. ${ }^{43}$

The most common chromosomal abnormality in intrinsic HES patients is an interstitial deletion in chromosome 4q12 that results in the expression of a fusion protein, FIP1L1 (Fip1-like 1)/PDGFRA, which has constitutive tyrosine kinase activity. Less common abnormalities include translocations on chromosomes $5 \mathrm{q} 33$ and $8 \mathrm{p} 11$ that result in PDGFRB and fibroblast growth factor receptor 1 (FGFRI) gene rearrangements, respectively. ${ }^{44}$ Because of the clonal nature of the eosinophilia, these forms of HES are now termed "PDGFR- or FGFR1-associated myeloproliferative neoplasms." These disorders share clinical and laboratory features with marked eosinophilia in the setting of cytogenetic abnormalities and/or increased bone marrow blasts, termed "chronic eosinophilic leukemia not otherwise specified (CEL-NOS)" (Table 1).

Patients with intrinsic eosinophilic disorders are often seriously ill, with end-organ damage such as endomyocardial fibrosis and mucosal ulcers, and are often resistant to agents commonly used to treat hypereosinophilia, such as prednisone. Despite this, most HES patients with mutations in PDGFR are exquisitely sensitive to the tyrosine kinase inhibitor, imatinib, with sustained clinical responses at doses as low as $100 \mathrm{mg}$ weekly in some cases. ${ }^{45}$ Interestingly, some patients with HES lacking the PDGFR mutations also respond to imatinib, suggesting that one or more additional imatinib-sensitive oncoproteins are implicated in the pathogenesis of HES. ${ }^{46}$ Furthermore, a multicenter clinic trial showed that mepolizumab was more effective than placebo in controlling peripheral blood eosinophil counts and facilitating corticosteroid withdrawal in patients with HES. ${ }^{47}$

Thrombotic and thromboembolic events are frequent complications of HES. Patients with evidence of cardiac involvement, neurologic and/or peripheral vascular symptoms of emboli are routinely anti-coagulated with warfarin, antiplatelet agents, or heparin. Unfortunately, many patients treated with anticoagulants continue to have thrombotic events thereby questioning the efficacy of such agents. Incomplete understanding of the mechanisms by which eosinophils affect coagulation has hindered our ability to optimally treat HESassociated coagulopathy. Interestingly, many patients with HES and long-standing eosinophilia have no evidence of coagulopathy.

The eosinophilia of HES has been associated with the presence of increased numbers of blood eosinophils with a relatively long half-life. Eosinophils from HES patients, in contrast to healthy individuals, express high levels of the cellular inhibitors of apoptosis protein-2 
(cIAP2) and survivin, which contribute to delayed apoptosis of these cells by inhibition of the caspase cascade. Mechanistic studies to induce eosinophil apoptosis have been conducted on mouse and human eosinophils, with the cross-linking of Siglec-8 on human eosinophils and Siglec-F on mouse eosinophils inducing apoptosis and resulting in rapid reduction in eosinophil numbers. 48,49 These and other findings suggest that an imbalance in apoptosis may be responsible in part for the sustained eosinophilia in HES and that measures to enhance eosinophil apoptosis could be of benefit in the treatment of these patients.

The taskforce recommends that future efforts should aim at:

- $\quad$ identifying other relevant genetic mutations for targeting tyrosine kinase activity associated with hypereosinophilia

- $\quad$ improving our understanding of the mechanisms and improving the treatment of HES coagulopathy

- $\quad$ exploring potential subsets of HESs for eosinophil apoptosis defects

- evaluating the utility of therapies targeting eosinophilopoiesis, eosinophil activation and eosinophil apoptosis in treating HES

\section{Eosinophil-Associated Respiratory Diseases}

Eosinophilic respiratory diseases are characterized by increased numbers of eosinophils in the peripheral blood, sputum, lung tissues, and bronchoalveolar lavage (BAL) fluid. Respiratory tract eosinophilia is not only a diagnostic feature and therapeutic target, but plays an important role in altered lung function in these disorders. ${ }^{50,51}$ Each of the eosinophilic respiratory diseases has distinguishing characteristics, prognosis, and, in some cases, responsiveness to treatment.

Acute eosinophilic pneumonia is manifested by fever, shortness of breath, cough and respiratory compromise. A chest x-ray usually reveals bilateral pulmonary infiltrates. Increased eosinophil numbers are seen in the lung, but not always in the blood. With severe episodes, respiratory support may be needed to maintain adequate oxygenation. Corticosteroids are effective treatment and in most cases, recovery is complete and permanent.

Chronic eosinophilic pneumonia onset is often indolent with symptoms including cough, weight loss, and progressive dyspnea. ${ }^{52}$ The majority of patients have peripheral blood eosinophilia, often more than 30\%, and co-existing BAL fluid eosinophilia. Systemic corticosteroids are the treatment of choice, but prevention of relapse often requires chronic, low-dose treatment with these agents.

Churg-Strauss syndrome (CSS), or allergic granulomatosis, is a complex, chronic, and often progressive multi-organ disease that is characterized by eosinophilic vasculitis, blood and lung eosinophilia, pulmonary infiltrates and other organ involvement. ${ }^{53,54} \mathrm{CSS}$ is distinguished from other pulmonary eosinophilic syndromes by the presence of asthma, involvement of multiple organs, such as the gastrointestinal tract and heart, and by the presence of anti-neutrophil cytoplasmic antibodies (ANCA) in almost half of the cases. Acute treatment includes corticosteroids, and for some, a remission-inducing drug like cyclophosphamide, but responses to treatment is variable and unpredictable. Recent pilot studies have found a steroid-sparing benefit of anti-IL-5 therapy in preventing relapse in CSS. ${ }^{55}$ Anti-IL-5 therapy has also shown promise in treatment of eosinophilic nasal polyposis, commonly seen in aspirin-exacerbated respiratory disease and in CSS. ${ }^{56}$

The taskforce recommends that future efforts should aim at: 
- identifying and validating lung-specific genomic or protein signatures for eosinophilic pulmonary syndromes

- validating the diagnostic utility of antibodies (e.g., ANCA) and of clinical measures (e.g., symptom scores) in eosinophilic lung diseases

- developing and validating new clinical diagnostic tools for CSS

\section{Overview}

The Taskforce on the Research Needs of Eosinophil-Associated Diseases (TREAD) was convened to address current unmet clinical and research needs related to human eosinophilassociated diseases. Cognizant of the diversity of eosinophil-associated diseases, the convened TREAD panel focused on specific organ-related eosinophil-associated diseases and broadly considered issues pertinent to the recognition, documentation, management, and prognosis of eosinophil-associated diseases. Common unmet needs and organ/disease unmet needs for eosinophil-associated diseases are summarized in Tables 2 and 3, respectively.

\section{Recommendations}

TREAD emphasizes the importance of eosinophil-associated diseases and has identified unmet needs of clinical practice and future research directions. TREAD recognizes that current clinical practice needs to benefit from future research developments. Accordingly, we summarize below both contemporarily recognized clinical needs and future oriented research needs.

\section{Clinical Needs}

\section{1) Eosinophil-associated disease-specific codes in the forthcoming ICD-10}

Current ICD-9 codes fail to identify many eosinophil-associated diseases (e.g., CSS) (Table 1). Patient advocacy groups succeeded in including codes in ICD-9 for eosinophil-related gastrointestinal diseases. New ICD-10 codes need to be specific for each eosinophilassociated disease to allow for accurate recording of prevalence and to facilitate medical insurance coverage for patients.

\section{2) Access to therapeutics for eosinophil-associated diseases that are not approved by the FDA}

With CSS as an example, there is no medication, including corticosteroids, approved for the treatment of this disease. Likewise for other eosinophil-associated diseases, the lack of formal FDA approval of any treatment becomes a basis for insurance companies to deny reimbursements for expensive therapies, e.g. interferon- $a$, for which published studies demonstrating therapeutic efficacy exist. Most eosinophil-associated diseases are uncommon and thus dissuade pharmaceutical companies from ever attempting to seek FDA approval for such "niche" diseases. For newer therapeutics, such as IL-5-neutralizing monoclonal antibodies, there needs to be new dialogue with the FDA over standards and outcomes that can ethically be met in assessing the safety and efficacy of these agents.

\section{3) Enhanced opportunities for collaborative efforts to improve the diagnosis, and management of eosinophil-associated diseases}

Cognizant that eosinophil-associated diseases are uncommon and patient populations are small, better team approaches are needed for the evaluation and management of these diseases. At present, some patients with eosinophil-associated diseases are referred to a limited number of expert medical centers. The development of a web-based resource for clinicians that can provide both guidance and resources for evaluating and managing 
patients would be of great value. This resource would make available interactions among primary care physicians, dermatologists, pulmonologists, gastroenterologists, rheumatologists, allergists, hematologists, clinician scientists and dietitians. TREAD recommends that commonly available web-based resource(s) be developed to serve several currently unmet needs:

a) Expanded access to contemporary clinical guidance on eosinophilassociated diseases-Clinical care providers in any locale should have access to current diagnostic and therapeutic guidelines and information regarding referrals to experts in eosinophil-associated diseases. This will improve the standard of care and also expand opportunities for patients to obtain expert evaluations and access to clinical trials.

\section{b) Access to recommended and available diagnostic testing methodologies} for eosinophil-associated diseases-As noted for individual eosinophil-associated diseases (Table 3), there are recommended approaches, ranging from immunostaining for released eosinophil proteins in biopsied tissues to expanded molecular diagnostics for chromosomal lesions that underlie some myelodysplastic eosinophil diseases. A central web-based resource would provide protocols for these assays, name commercial sites that provide these assays, or if not widely available, identify research-interested medical centers that could provide these analyses.

\section{Research Needs}

\section{1) Support research on the fundamental immunobiology of human eosinophils}

Advances in our understanding of the immunobiology of eosinophils in the past arose from $\mathrm{NIH}$-sponsored research that was not specifically disease focused (including studies demonstrating that human eosinophils were sources of secreted cytokines, chemokines and other mediators). Research funded by NIH and other interested organizations should continue to support such studies because they will provide novel and informative insights into eosinophil roles in eosinophil-associated diseases and will unveil novel therapeutic targets.

\section{2) Support clinical studies of human eosinophil-associated diseases}

The pathophysiologic mechanisms by which eosinophils contribute to these diseases remain poorly understood and reliable biomarkers of eosinophil involvement and of disease activity are largely lacking. Without such knowledge, our current approaches towards disease management are imprecise and the development of new therapies is hindered. A related clinical research topic is the development of biomarkers that both identify various states of eosinophil activation and/or involvement in disease. Such tests would serve as non-invasive (blood) tests or biopsy based analyses such as the EoE biopsy transcriptome analysis.

\section{3) Develop animal models of human eosinophil production, migration, accumulation, function and organ-targeted diseases}

Existing murine models often do not recapitulate eosinophil-associated human diseases although they can be informative by elucidating the biologic function of eosinophils and their immunopathogenic activities. New approaches could include "humanized" mouse models in which immunocompromised mice are repopulated with human cells, although species differences in soluble mediators and tissue proteins may also need to be dealt with in order to fully recreate human eosinophil biology in an animal model. 


\section{4) Develop new eosinophil-targeted therapeutics appropriate for eosinophil-associated diseases}

This goal requires the combined effort of clinicians, researchers and pharmaceutical companies. Awareness that many eosinophil-associated diseases are considered "orphan" diseases due to their infrequency should guide regulatory approval for new therapeutics. Given that nearly all current treatments for eosinophil-associated diseases are used off-label, clear clinically-relevant endpoints agreed upon as a result of proactive discussions with the FDA will be needed to make significant progress in this area.

\section{5) Access to shared databases related to eosinophil-associated diseases}

TREAD recommends that web-based databases be developed:

\section{a) A biospecimen database shared among centers and investigators with} interests in eosinophil-associated diseases-Given that there is a common interest in identifying biomarkers of disease activity in eosinophil-associated diseases, a website that can share findings of candidate biomarkers would facilitate other centers testing these in their patients and stored samples. The investigator website would also provide standards for storing and saving biospecimens from patients with eosinophil-associated diseases for later analyses. It should be noted that adequate storage and quality assurance of biospecimens should be a priority for any collaborative, multicenter studies of eosinophil-associated diseases. The use of standardized and/or central storage facilities will likely decrease biospecimen variance and degradation.

b) A patient-based registry of eosinophil-associated diseases-Recently, a Registry of EGIDs has been launched (www.regid.org) which has the potential to connect clinical researchers and patients, provide an opportunity to examine the natural history of EGIDs and provide a source of patients for research studies. TREAD encourages the development of new registries, or the expansion of the EGID registry, to include all other eosinophil-associated diseases. TREAD recommends that www.regid.org be web-linked across patient advocacy groups, governmental funding agencies and eosinophil clinical research centers. TREAD is aware of the costs associated with maintaining an up-to-date database and given resources prioritizes this amongst other compelling clinical and research needs.

Participants at the Workshop:

\begin{tabular}{lll}
\hline Bruce S. Bochner, MD & Wendy Book, MD & William W. Busse, MD \\
Joseph Butterfield, MD & Wendy Davidson, PhD & Gang Dong, PhD \\
Ms. Victoria Delano & Mrs. Jane Dion & Mr. John Dion \\
Peter Gergen, MD & Gerald J. Gleich, MD & Margarita Gomez, MD \\
Ms. Sheryl Grossman & Frank Hamilton, MD & Amy D. Klion, MD \\
Ms. Ellyn Kodroff & Megan Miller, PhD & Michael Minnicozzi, PhD \\
$\begin{array}{l}\text { Redwan Moqbel, PhD } \\
\text { Marc E. Rothenberg, MD, PhD }\end{array}$ & Andrew Mulberg, MD & Marshall Plaut, MD \\
$\begin{array}{l}\text { Lawrence B. Schwartz, MD } \\
\text { Michael E. Wechsler, MD }\end{array}$ & Julie Schwaninger, MS & Daniel Rotrosen, MD \\
\hline
\end{tabular}




\section{Acknowledgments}

The authors wish to thank the members of the patient advocacy groups; APFED, the Churg-Strauss Association and CURED, along with members from FDA for attending and offering their valuable insight; and Drs. Alkis Togias and Dan Rotrosen at the National Institute of Allergy and Infectious Diseases for their helpful feedback and suggestions on this document. The Taskforce also wishes to thank Julie Schwaninger for her professional and organizational skills and Ms. Jacqueline Schaffer for her outstanding artwork.

Funding Support: The workshop was supported by funds from the Divisions of Intramural and Extramural Research, National Institute of Allergy and Infectious Diseases and the Office of Disease Prevention.

\section{Abbreviations}

ANCA

BAL

CEL-NOS

cIAP2

CSS

EGID

EoE

FGFR1

FIP1L1

GERD

GI

GM-CSF

HES

IDO

IL

PDGFRA

PPI

Th2 T

TSLP anti-neutrophil cytoplasmic antibodies

bronchoalveolar lavage

chronic eosinophilic leukemia, not otherwise specified

cellular inhibitor of apoptosis protein-2

Churg-Strauss syndrome

eosinophilic gastrointestinal disorders

eosinophilic esophagitis

fibroblast growth factor receptor 1

Fip1-like 1

gastroesophageal reflux disease

gastrointestinal

granulocyte-macrophage colony-stimulating factor

hypereosinophilic syndrome

indoleamine 2,3 dioxygenase

Interleukin

platelet-derived growth factor receptor a

proton-pump inhibitor

helper cell type 2

thymic stromal lymphopoietin

\section{References}

1. Bochner BS, Gleich GJ. What targeting eosinophils has taught us about their role in diseases. J Allergy Clin Immunol. 2010; 126:16-25. [PubMed: 20434203]

2. Simon D, Wardlaw A, Rothenberg ME. Organ-specific eosinophilic disorders of the skin, lung and gastrointestinal tract. J Allergy Clin Immunol. 2010; 126:45-9. [PubMed: 20639008]

3. Matthews AN, Friend DS, Zimmerrmann N, Sarafi MN, Luster AD, Pearlman E, et al. Eotaxin is required for the baseline level of tissue eosinophils. Proc Natl Acad Sci USA. 1998; 95:6273-8. [PubMed: 9600955]

4. Tulic MK, Andrews D, Crook ML, Charles A, Tourigny MR, Moqbel R, et al. Changes in thymic regulatory T-cell maturation from birth to puberty: differences in atopic children. J Allergy Clin Immunol. 2012; 129:199-206. e1-4. [PubMed: 22104606] 
5. Tulic MK, Sly PD, Andrews D, Crook M, Davoine F, Odemuyiwa SO, et al. Thymic indoleamine 2,3-dioxygenase-positive eosinophils in young children: potential role in maturation of the naive immune system. Am J Pathol. 2009; 175:2043-52. [PubMed: 19815714]

6. Akuthota P, Wang HB, Spencer LA, Weller PF. Immunoregulatory roles of eosinophils: a new look at a familiar cell. Clin Exp Allergy. 2008; 38:1254-63. [PubMed: 18727793]

7. Makepeace BL, Martin C, Turner JD, Specht S. Granulocytes in helminth infection -- who is calling the shots? Curr Med Chem. 2012; 19:1567-86. [PubMed: 22360486]

8. Lee JJ, Dimina D, Macias MP, Ochkur SI, McGarry MP, O’Neill KR, et al. Defining a link with asthma in mice congenitally deficient in eosinophils. Science. 2004; 305:1773-6. [PubMed: 15375267]

9. Humbles AA, Lloyd CM, McMillan SJ, Friend DS, Xanthou G, McKenna EE, et al. A critical role for eosinophils in allergic airways remodeling. Science. 2004; 305:1776-9. [PubMed: 15375268]

10. Lee JJ, Jacobsen EA, McGarry MP, Schleimer RP, Lee NA. Eosinophils in health and disease: the LIAR hypothesis. Clin Exp Allergy. 2010; 40:563-75. [PubMed: 20447076]

11. Wu D, Molofsky AB, Liang HE, Ricardo-Gonzalez RR, Jouihan HA, Bando JK, et al. Eosinophils sustain adipose alternatively activated macrophages associated with glucose homeostasis. Science. 2011; 332:243-7. [PubMed: 21436399]

12. Chu VT, Frohlich A, Steinhauser G, Scheel T, Roch T, Fillatreau S, et al. Eosinophils are required for the maintenance of plasma cells in the bone marrow. Nat Immunol. 2011; 12:151-9. [PubMed: 21217761]

13. Odemuyiwa SO, Ghahary A, Li Y, Puttagunta L, Lee JE, Musat-Marcu S, et al. Cutting edge: human eosinophils regulate $\mathrm{T}$ cell subset selection through indoleamine 2,3-dioxygenase. J Immunol. 2004; 173:5909-13. [PubMed: 15528322]

14. Wehling-Henricks M, Sokolow S, Lee JJ, Myung KH, Villalta SA, Tidball JG. Major basic protein-1 promotes fibrosis of dystrophic muscle and attenuates the cellular immune response in muscular dystrophy. Hum Mol Genet. 2008; 17:2280-92. [PubMed: 18430716]

15. Simson L, Ellyard JI, Dent LA, Matthaei KI, Rothenberg ME, Foster PS, et al. Regulation of carcinogenesis by IL-5 and CCL11: a potential role for eosinophils in tumor immune surveillance. J Immunol. 2007; 178:4222-9. [PubMed: 17371978]

16. Goldman M, Le Moine A, Braun M, Flamand V, Abramowicz D. A role for eosinophils in transplant rejection. Trends Immunol. 2001; 22:247-51. [PubMed: 11323281]

17. Masterson JC, Furuta GT, Lee JJ. Update on clinical and immunological features of eosinophilic gastrointestinal diseases. Curr Opin Gastroenterol. 2011; 27:515-22. [PubMed: 21897226]

18. Furuta GT, Liacouras CA, Collins MH, Gupta SK, Justinich C, Putnam PE, et al. Eosinophilic esophagitis in children and adults: a systematic review and consensus recommendations for diagnosis and treatment. Gastroenterology. 2007; 133:1342-63. [PubMed: 17919504]

19. Liacouras CA, Furuta GT, Hirano I, Atkins D, Attwood SE, Bonis PA, et al. Eosinophilic esophagitis: updated consensus recommendations for children and adults. J Allergy Clin Immunol. 2011; 128:3-20. e6. quiz 1-2. [PubMed: 21477849]

20. Blanchard C, Wang N, Stringer KF, Mishra A, Fulkerson PC, Abonia JP, et al. Eotaxin-3 and a uniquely conserved gene-expression profile in eosinophilic esophagitis. J Clin Invest. 2006; 116:536-47. [PubMed: 16453027]

21. Abonia JP, Blanchard C, Butz BB, Rainey HF, Collins MH, Stringer K, et al. Involvement of mast cells in eosinophilic esophagitis. J Allergy Clin Immunol. 2010; 126:140-9. [PubMed: 20538331]

22. Straumann A, Aceves SS, Blanchard C, Collins MH, Furuta GT, Hirano I, et al. Pediatric and adult eosinophilic esophagitis: similarities and differences. Allergy. 2012; 67:477-90. [PubMed: 22313241]

23. Gonsalves N, Yang GY, Doerfler B, Ritz S, Ditto AM, Hirano I. Elimination diet effectively treats eosinophilic esophagitis in adults; food reintroduction identifies causative factors. Gastroenterology. 2012; 142:1451-9. e1. [PubMed: 22391333]

24. DeBrosse CW, Franciosi JP, King EC, Butz BK, Greenberg AB, Collins MH, et al. Long-term outcomes in pediatric-onset esophageal eosinophilia. J Allergy Clin Immunol. 2011; 128:132-8. [PubMed: 21636117] 
25. DeBrosse CW, Collins MH, Butz BK Buckmeier, Allen CL, King EC, Assa'ad AH, et al. Identification, epidemiology, and chronicity of pediatric esophageal eosinophilia, 1982-1999. J Allergy Clin Immunol. 2010; 126:112-9. [PubMed: 20620567]

26. Mishra A, Hogan SP, Lee JJ, Foster PS, Rothenberg ME. Fundamental signals that regulate eosinophil homing to the gastrointestinal tract. J Clin Invest. 1999; 103:1719-27. [PubMed: 10377178]

27. Hogan SP, Foster PS, Rothenberg ME. Experimental analysis of eosinophil-associated gastrointestinal diseases. Curr Opin Allergy Clin Immunol. 2002; 2:239-48. [PubMed: 12045421]

28. Blanchard C, Wang N, Rothenberg ME. Eosinophilic esophagitis: pathogenesis, genetics, and therapy. J Allergy Clin Immunol. 2006; 118:1054-9. [PubMed: 17088129]

29. Noel RJ, Rothenberg ME. Eosinophilic esophagitis. Curr Opin Pediatr. 2005; 17:690-4. [PubMed: 16282772]

30. Leiferman KM, Peters MS. Reflections on eosinophils and flame figures: where there's smoke there's not necessarily Wells syndrome. Arch Dermatol. 2006; 142:1215-8. [PubMed: 16983010]

31. Effat KG. Angiolymphoid hyperplasia with eosinophilia of the auricle: progression of histopathological changes. J Laryngol Otol. 2006; 120:411-3. [PubMed: 16696882]

32. Chen H, Thompson LD, Aguilera NS, Abbondanzo SL. Kimura disease: a clinicopathologic study of 21 cases. Am J Surg Pathol. 2004; 28:505-13. [PubMed: 15087670]

33. Gleich GJ, Schroeter AL, Marcous JP, Sachs MI, O’Connell EJ, Kohler PF. Episodic angioedema associated with eosinophilia. N Engl J Med. 1984; 310:1621-6. [PubMed: 6727934]

34. Wolf C, Pehamberger H, Breyer S, Leiferman KM, Wolff K. Episodic angioedema with eosinophilia. J Am Acad Dermatol. 1989; 20:21-7. [PubMed: 2521494]

35. Butterfield JH, Leiferman KM, Abrams J, Silver JE, Bower J, Gonchoroff N, et al. Elevated serum levels of interleukin-5 in patients with the syndrome of episodic angioedema and eosinophilia. Blood. 1992; 79:688-92. [PubMed: 1732010]

36. Antic M, Lautenschlager S, Itin PH. Eosinophilic fasciitis 30 years after - what do we really know? Report of 11 patients and review of the literature. Dermatology. 2006; 213:93-101. [PubMed: 16902285]

37. Bischoff L, Derk CT. Eosinophilic fasciitis: demographics, disease pattern and response to treatment: report of 12 cases and review of the literature. Int J Dermatol. 2008; 47:29-35. [PubMed: 18173597]

38. Lakhanpal S, Ginsburg WW, Michet CJ, Doyle JA, Moore SB. Eosinophilic fasciitis: clinical spectrum and therapeutic response in 52 cases. Semin Arthritis Rheum. 1988; 17:221-31. [PubMed: 3232080]

39. Hertzman PA, Blevins WL, Mayer J, Greenfield B, Ting M, Gleich GJ. Association of the eosinophilia-myalgia syndrome with the ingestion of tryptophan. N Engl J Med. 1990; 322:86973. [PubMed: 2314421]

40. Weaver J, Bergfeld WF. Quantitative analysis of eosinophils in acute graft- versus-host disease compared with drug hypersensitivity reactions. Am J Dermatopathol. 2010; 32:31-4. [PubMed: 19730082]

41. Simon HU, Rothenberg ME, Bochner BS, Weller PF, Wardlaw AJ, Wechsler ME, et al. Refining the definition of hypereosinophilic syndrome. J Allergy Clin Immunol. 2010; 126:45-9. [PubMed: 20639008]

42. Ogbogu PU, Bochner BS, Butterfield JH, Gleich GJ, Huss-Marp J, Kahn JE, et al. Hypereosinophilic syndrome: A multicenter, retrospective analysis of clinical characteristics and response to therapy. J Allergy Clin Immunol. 2009; 124:1319-25. [PubMed: 19910029]

43. Valent P, Gleich GJ, Reiter A, Roufosse F, Weller PF, Hellmann A, et al. Pathogenesis and classification of eosinophil disorders: a review of recent developments in the field. Expert Rev Hematol. 2012; 5:157-76. [PubMed: 22475285]

44. Lierman E, Cools J. Recent breakthroughs in the understanding and management of chronic eosinophilic leukemia. Expert Rev Anticancer Ther. 2009; 9:1295-304. [PubMed: 19761433]

45. Cools J, DeAngelo DJ, Gotlib J, Stover EH, Legare RD, Cortes J, et al. A tyrosine kinase created by fusion of the PDGFRA and FIP1L1 genes as a therapeutic target of imatinib in idiopathic hypereosinophilic syndrome. N Engl J Med. 2003; 348:1201-14. [PubMed: 12660384] 
46. Butterfield JH. Success of short-term, higher-dose imatinib mesylate to induce clinical response in FIP1L1-PDGFRalpha-negative hypereosinophilic syndrome. Leuk Res. 2009; 33:1127-9. [PubMed: 19144405]

47. Rothenberg ME, Klion AD, Roufosse FE, Kahn JE, Weller PF, Simon HU, et al. Treatment of patients with the hypereosinophilic syndrome with mepolizumab. N Engl J Med. 2008; 358:121528. [PubMed: 18344568]

48. Ackerman SJ, Bochner BS. Mechanisms of eosinophilia in the pathogenesis of hypereosinophilic disorders. Immunol Allergy Clin North Am. 2007; 27:357-75. [PubMed: 17868854]

49. Kiwamoto T, Kawasaki N, Paulson JC, Bochner BS. Siglec-8 as a drugable target to treat eosinophil and mast cell-associated conditions. Pharmacol Ther. doiorg/101016/ jpharmthera2012060052012.

50. Wechsler ME. Pulmonary eosinophilic syndromes. Immunol Allergy Clin North Am. 2007; 27:477-92. [PubMed: 17868860]

51. Perez, ER Fernandez; Olson, AL.; Frankel, SK. Eosinophilic lung diseases. Med Clin North Am. 2011; 95:1163-87. [PubMed: 22032433]

52. Marchand E, Cordier JF. Idiopathic chronic eosinophilic pneumonia. Semin Respir Crit Care Med. 2006; 27:134-41. [PubMed: 16612764]

53. Guillevin L, Cohen P, Gayraud M, Lhote F, Jarrousse B, Casassus P. Churg-Strauss syndrome. Clinical study and long-term follow-up of 96 patients. Medicine (Baltimore). 1999; 78:26-37. [PubMed: 9990352]

54. Hellmich B, Ehlers S, Csernok E, Gross WL. Update on the pathogenesis of Churg-Strauss syndrome. Clin Exp Rheumatol. 2003; 21:S69-77. [PubMed: 14740430]

55. Kim S, Marigowda G, Oren E, Israel E, Wechsler ME. Mepolizumab as a steroid-sparing treatment option in patients with Churg-Strauss syndrome. J Allergy Clin Immunol. 2010; 125:1336-43. [PubMed: 20513524]

56. Gevaert P, Van Bruaene N, Cattaert T, Van Steen K, Van Zele T, Acke F, et al. Mepolizumab, a humanized anti-IL-5 mAb, as a treatment option for severe nasal polyposis. J Allergy Clin Immunol. 2011; 128:989-95. [PubMed: 21958585] 
Complications of Eosinophil-Associated Diseases

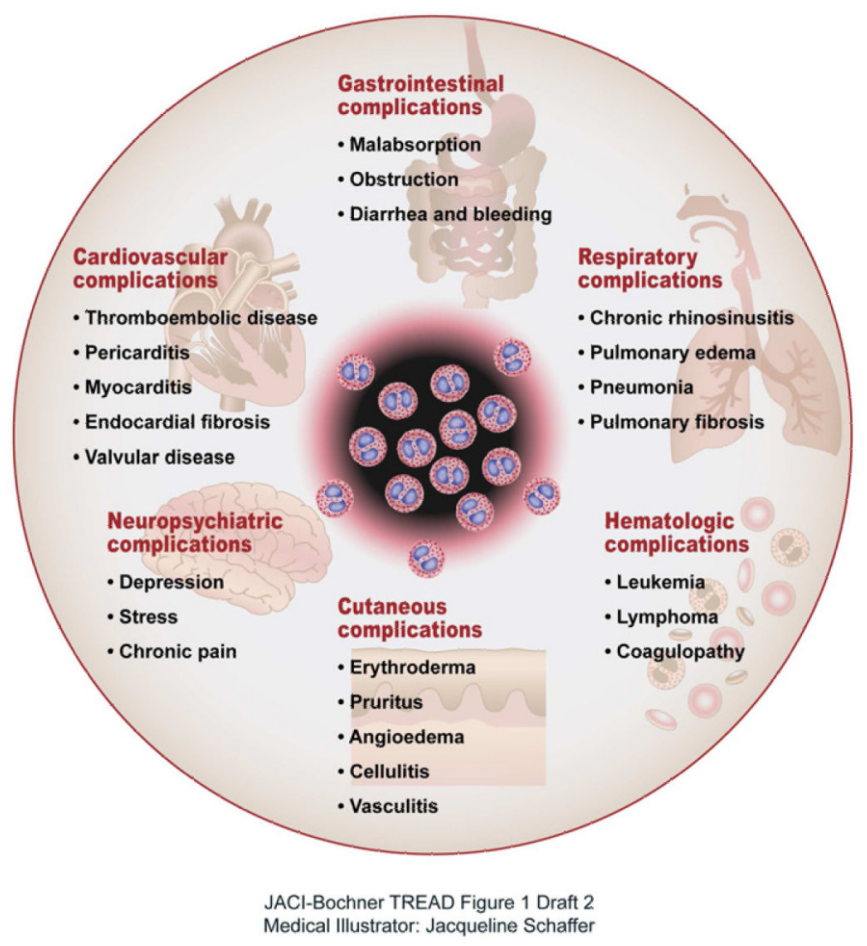

Figure 1.

Complications of Eosinophil-Associated Diseases 
Table 1

Inadequacies of ICD-9 CM diagnosis codes for various eosinophil-associated diseases.

\begin{tabular}{|l|l|l|}
\hline $\begin{array}{l}\text { Eosinophil-Associated } \\
\text { Disease }\end{array}$ & $\begin{array}{l}\text { ICD-9 CM Codes Currently } \\
\text { Available for (named disorders) }\end{array}$ & $\begin{array}{l}\text { Eosinophil- } \\
\text { Disease } \\
\text { Appropriate? }\end{array}$ \\
\hline $\begin{array}{l}\text { Chronic eosinophilic leukemia } \\
\text { (CEL) }\end{array}$ & $\begin{array}{l}205.1 \text { (CMyeloidL) } \\
207.8 \text { (CEL-NOS) } \\
238.71 \text { ('other' leukemia) }\end{array}$ & No \\
\hline Churg-Strauss Syndrome & $\begin{array}{l}447.6 \\
\text { (Vasculitis, not otherwise specified) }\end{array}$ & No \\
\hline Eosinophilic cystitis & 595.9 (Cystitis, unspecified) & No \\
\hline Eosinophilic colitis & 558.42 & Yes \\
\hline Eosinophilic esophagitis & 530.13 & Yes \\
\hline Eosinophilic fasciitis & 729.4 (Fasciitis, unspecified) & No \\
\hline Eosinophilic folliculitis & 704.8 (Other unspecified diseases of & No \\
\hline $\begin{array}{l}\text { the follicle) } \\
\text { Eosinophilic gastritis }\end{array}$ & 535.7 & Yes \\
\hline $\begin{array}{l}\text { Eosinophilic gastritis and } \\
\text { colitis }\end{array}$ & 558.4 & Yes \\
\hline Eosinophilic pneumonia & 518.3 (Pulmonary eosinophilia) & No \\
\hline Nasal polyposis & 288.3 (Eosinophilia) & Yes \\
\hline
\end{tabular}

By consensus opinion of the authors of this report

ICD-9 CM; International Classification of Diseases, Clinical Modification, and based on the World Health Organization's Ninth Revision 
Table 2

Common Unmet Needs Across Eosinophil-Associated Diseases

\begin{tabular}{|c|c|c|}
\hline $\begin{array}{l}\text { Common Needs Across } \\
\text { Eosinophil- } \\
\text { Approaches Associated }\end{array}$ & Diseases & \\
\hline $\begin{array}{l}\text { Creation of validated diagnostic } \\
\text { codes to } \\
\text { identify and define patient subsets }\end{array}$ & 1 & Develop and utilize an expanded list of eosinophil disease specific ICD-10 CM codes \\
\hline $\begin{array}{l}\text { In-depth analysis of biopsy } \\
\text { samples }\end{array}$ & $\begin{array}{l}1 \\
2 \\
3 \\
4\end{array}$ & $\begin{array}{l}\text { Standardize biopsies and their locations by: number, type and size of high power fields } \\
\text { (hpfs) to count; mean versus peak eosinophil counts/hpfs or eosinophils per unit area } \\
\text { Identify and validate eosinophil involvement by measuring degranulation (e.g., tissue } \\
\text { immunohistochemical staining for eosinophil granule proteins) } \\
\text { Identify and validate alternative markers of eosinophil activation } \\
\text { Perform assessments for alternative markers of disease using genetic, proteomic and } \\
\text { glycomic analytic approaches on standardized biopsy specimens }\end{array}$ \\
\hline $\begin{array}{l}\text { Reliable invasive and non- } \\
\text { invasive } \\
\text { testing for diagnosis of disease, } \\
\text { assessment of control and } \\
\text { prevention of } \\
\text { exacerbations }\end{array}$ & $\mathbf{1}$ & $\begin{array}{l}\text { Identify and validate disease specific predictors, including biomarkers } \\
\text { Develop and validate disease-specific quality of life questionnaires and disease control } \\
\text { indices }\end{array}$ \\
\hline $\begin{array}{l}\text { Mechanistic understanding of the } \\
\text { specific contributing roles of } \\
\text { eosinophils } \\
\text { in various eosinophil-associated } \\
\text { diseases }\end{array}$ & 1 & $\begin{array}{l}\text { Advance basic and clinical research on the immunobiology of eosinophils to better } \\
\text { delineate the normal and disease associated functions of eosinophils }\end{array}$ \\
\hline $\begin{array}{l}\text { Development of accessible patient } \\
\text { registries }\end{array}$ & $\begin{array}{l}1 \\
2 \\
3\end{array}$ & $\begin{array}{l}\text { By nature, rare diseases are limited in the number of patients. Expand the use of existing } \\
\text { registries e.g., REGID (www.regid.org) } \\
\text { Create and expand biological sample repositories for future use } \\
\text { Utilize patient advocacy groups to increase awareness of registries to clinician researchers } \\
\text { and referring practitioners }\end{array}$ \\
\hline $\begin{array}{l}\text { Improved guidance and success of } \\
\text { relevant clinical trials in rare } \\
\text { disease } \\
\text { patient populations }\end{array}$ & 2 & $\begin{array}{l}\text { Develop earlier communications amongst FDA, funding agencies, the pharmaceutical } \\
\text { industry and clinician-scientists to define parameters, including clinically- meaningful end } \\
\text { points, for treatment studies, patient selection, and compassionate use or orphan- disease } \\
\text { utilization } \\
\text { Continue and expand proactive engagement and conversations among clinical investigators } \\
\text { and relevant governmental agencies }\end{array}$ \\
\hline $\begin{array}{l}\text { Expand the number of useful } \\
\text { therapeutics (disease modifying, } \\
\text { controlling or curative) for } \\
\text { treating } \\
\text { eosinophil-associated diseases }\end{array}$ & $\begin{array}{l}1 \\
2 \\
3\end{array}$ & $\begin{array}{l}\text { Formally test existing licensed therapeutics e.g., interferon-a, for new indications. } \\
\text { Explore with industry the use of anti-IL5, anti-IL-5 receptor and other future eosinophil- } \\
\text { selective monoclonal antibody therapies for the treatment of eosinophil-associated diseases } \\
\text { Encourage research and development of novel biologic and non-biologic therapeutics, as } \\
\text { well as safer ways to deliver existing therapeutics including glucocorticosteroids }\end{array}$ \\
\hline
\end{tabular}


Table 3

Organ/Disease Specific Unmet Needs for Eosinophil-Associated Diseases

\begin{tabular}{|c|c|c|}
\hline Disease Entity & Unmet & ed to be Addressed \\
\hline $\begin{array}{l}\text { Eosinophil } \\
\text { Gastrointestinal Disorders }\end{array}$ & $\begin{array}{l}6 \\
7\end{array}$ & $\begin{array}{l}\text { Identify best method for diagnosis including exclusion of esophageal acid/nonacid disease as the } \\
\text { cause of EoE (e.g., PPI therapy and diagnostic testing) } \\
\text { Formulate and validate criteria to diagnose eosinophilic diseases outside of the esophagus } \\
\text { Identify the relationship, if any, to other inflammatory bowel diseases } \\
\text { Develop and validate methods for testing of adults and children to help guiding dietary exclusion } \\
\text { protocols } \\
\text { Define optimal frequency and validate the need of endoscopic follow-up } \\
\text { Understand the cause of breakdown in oral food tolerance } \\
\text { Understand the mechanisms and prevent tissue remodeling, stricture formation and other disease } \\
\text { complications. } \\
\text { Non-invasive and invasive diagnostic tests for assessing diagnosis and disease activity. } \\
\text { Understand genetic underpinning and its interaction with the environment (e.g. food). }\end{array}$ \\
\hline $\begin{array}{l}\text { Eosinophil-Associated } \\
\text { Skin and Fibrotic Diseases }\end{array}$ & $\begin{array}{l}1 \\
2 \\
3\end{array}$ & $\begin{array}{l}\text { Define the relationship, if any, of skin-specific conditions with underlying systemic disorders } \\
\text { Standardize and validate methods for skin biopsies to improve diagnosis and treatment } \\
\text { Develop plans for inter-governmental agency communication and sourcing for responding to any } \\
\text { future epidemic outbreaks of eosinophil-associated diseases }\end{array}$ \\
\hline $\begin{array}{l}\text { Eosinophil-Associated } \\
\text { Cardiovascular Diseases }\end{array}$ & $\begin{array}{l}2 \\
3 \\
4\end{array}$ & $\begin{array}{l}\text { Improve and validate non-invasive diagnostic testing for detecting eosinophil-induced cardiac } \\
\text { damage } \\
\text { Improve therapies to block the progression of eosinophil-mediated cardiac damage } \\
\text { Advance our mechanistic understanding of eosinophil-mediated cardiac damage } \\
\text { Develop optimal preventive and acute treatment approaches }\end{array}$ \\
\hline $\begin{array}{l}\text { Eosinophil-Associated } \\
\text { Hematological Diseases }\end{array}$ & 1 & $\begin{array}{l}\text { Identify other relevant mutations for targeting tyrosine kinase activity that is mediating } \\
\text { hypereosinophilia } \\
\text { Improve our understanding and treatment of HES coagulopathy } \\
\text { Explore whether there are subsets of HESs with associated eosinophil apoptosis defects, how } \\
\text { common such defects might be, and whether therapies that enhance eosinophil apoptosis would be } \\
\text { useful in treating HESs }\end{array}$ \\
\hline $\begin{array}{l}\text { Eosinophil-Associated } \\
\text { Respiratory Diseases }\end{array}$ & 5 & $\begin{array}{l}\text { Identify and validate lung-specific genomic and protein signatures among eosinophilic pulmonary } \\
\text { syndromes } \\
\text { Validate the diagnostic utility of antibodies (e.g., ANCA) and clinical measures (e.g., symptom } \\
\text { scores) in eosinophilic lung diseases } \\
\text { Develop and validate new clinical diagnostic tools and ICD-10 CM codes for CSS and other } \\
\text { eosinophilic lung diseases } \\
\text { Determine whether CSS represents a single or multiple nosologic entities } \\
\text { Non-invasive and invasive diagnostic tests for assessing diagnosis and disease activity }\end{array}$ \\
\hline $\begin{array}{l}\text { Eosinophils and the LIAR } \\
\text { Hypothesis }\end{array}$ & $\begin{array}{l}1 \\
2\end{array}$ & $\begin{array}{l}\text { Understand the roles of eosinophils in innate immunity and other eosinophil functions } \\
\text { Assess for potential unwanted immune consequences due to targeting eosinophils and their function }\end{array}$ \\
\hline
\end{tabular}

